\title{
Epoxy/Polyhedral Oligomeric Silsesquioxane Nanocomposites from Octakis(glycidyldimethylsiloxy)octasilsesquioxane and Small-Molecule Curing Agents
}

\author{
YING-LING LIU, ${ }^{1,2}$ GUNG-PEI CHANG, ${ }^{1,2}$ KEH-YING HSU, ${ }^{1}$ FENG-CHIH CHANG ${ }^{3}$ \\ ${ }^{1}$ Department of Chemical Engineering, Chung Yuan Christian University, Chungli, Taoyuan 320, Taiwan \\ ${ }^{2}$ R\&D Center for Membrane Technology, Chung Yuan Christian University, Chungli, Taoyuan 320, Taiwan \\ ${ }^{3}$ Department of Applied Chemistry, National Chiao Tung University, Hsinchu 300, Taiwan
}

Received 24 February 2006; accepted 31 March 2006

DOI: 10.1002 / pola.21484

Published online in Wiley InterScience (www.interscience.wiley.com).

\begin{abstract}
Epoxy/polyhedral oligomeric silsesquioxane (POSS) nanocomposites were obtained from octakis(glycidyldimethylsiloxy)octasilsesquioxane (OG) and diglycidyl ether of bisphenol A cured with small-molecule curing agents of diethylphosphite (DEP) and dicyandiamide (DICY). An increase in the POSS contents of the nanocomposites and an improvement in the nanocomposite homogeneity were observed with the use of the small-molecule curing agents. Phosphorus in DEP and nitrogen in DICY also performed synergism with POSS for thermal stability enhancement and flammability improvement in the nanocomposites. The nanocomposites possessing high OG contents exhibited good thermal stability, improved flammability, and high storage moduli. (C) 2006 Wiley Periodicals, Inc. J Polym Sci Part A: Polym Chem 44: 38253835, 2006
\end{abstract}

Keywords: curing of polymers; nanocomposites; silicons; crosslinking

\section{INTRODUCTION}

Polyhedral oligomeric silsesquioxanes (POSSs) are useful molecular nanobuilding blocks in the formation of organic-inorganic nanocomposites. ${ }^{1-9}$ In contrast to conventional inorganic fillers, POSSs have the advantages of monodispersed size, low density, high thermal stability, and controlled functionalities. The functional groups in the organic substituents bring chemical versatility to POSSs and make POSSs widely compatible with various organic polymers. ${ }^{10-16} \mathrm{Ep}$ oxy resin/POSS nanocomposites are the most

Correspondence to: Y.-L. Liu (E-mail: ylliu@cycu.edu.tw) Journal of Polymer Science: Part A: Polymer Chemistry, Vol. 44, 3825-3835 (2006) @ 2006 Wiley Periodicals, Inc. studied of polymer-POSS nanocomposites, as epoxy resins are the most commercially successful materials known as composite matrices. ${ }^{17-36}$

Laine and coworkers ${ }^{20-24}$ reported a series of works on the preparation of epoxy-POSS monomers and their polymers. Octakis(glycidyldimethylsiloxy)octasilsesquioxane (OG) is the most studied epoxy-POSS compound. Epoxy-POSS composites prepared from OG and 4,4-diaminodiphenylmethane (DDM) exhibit tensile moduli comparable to and thermal stability better than those of conventional DDM-cured diglycidyl ether of bisphenol A (DGEBA) resins. ${ }^{20,21}$ Similar properties have also been observed with 4,4diaminodiphenylsulfone-cured OG composites. ${ }^{22}$ Recent studies used phenylenediamines as cur- 
ing agents in the preparation of epoxy-POSS nanocomposites, aiming to reduce the steric hindrance in curing reactions and increase the crosslinking densities of cured resins. ${ }^{31,34} \mathrm{Be}-$ sides being used as a multifunctional monomer, OG is also a reactive additive used to modify epoxy resins. POSS-modified DGEBA epoxy resins have been reported. ${ }^{17,24-27}$ The presence of POSS cages in nanocomposites reduces their dielectric constant, broadens the glass-transition behavior, and increases the storage modulus. However, enhancements of the glass-transition temperatures $\left(T_{\mathrm{g}}\right.$ 's) and thermal stabilities are not always observed with POSS-modified epoxy resins.

Curing agents strongly affect the structure and thermomechanical properties of crosslinked epoxy resins. In this work, two small-molecule curing agents of dicyandiamide (DICY) and diethylphosphite (DEP) were used in the preparation of epoxy-POSS nanocomposites. DICY is widely used in the manufacture of FR-4 printed circuit boards. DEP is a thermally latent curing agent. ${ }^{37}$ Phosphorus in DEP also potentially enhances the flame-retardant properties of epoxy resins. ${ }^{37-40}$ In addition, DICY and DEP potentially reduce the steric hindrance in curing reactions, increase the reaction conversions, and improve the homogeneity of the resulting nanocomposites. ${ }^{36}$ The morphology and thermal properties of the prepared nanocomposites are examined and discussed.

\section{EXPERIMENTAL}

\section{Materials}

OG, purchased from Hybrid Plastics, Inc. (Fountain Valley, CA), was used as received. DGEBA (BE188; epoxy equivalent weight $=188 \mathrm{~g} / \mathrm{mol}$ ) was received from Chang Chun Plastics Co. (Taiwan). DICY and DEP were purchased from Aldrich Co. and used as curing agents in this work.

\section{Equipment}

Fourier transform infrared (FTIR) spectra were recorded with a PerkinElmer Spectrum One FTIR apparatus equipped with an attenuatedtotal-reflectance accessory. The fracture surface morphology of the cured hybrid resins was observed with a scanning electron microscope (JSM-6500F, JEOL, Japan). Nanocomposite sam- ples were put into liquid nitrogen. The quenched samples were taken out and broken down with pliers. The fractured surface was then applied to scanning electron microscopy (SEM) observation. Differential scanning calorimetry (DSC) thermograms were recorded with a Thermal Analysis DSC-Q10 differential scanning calorimeter. The testing range was $30-300{ }^{\circ} \mathrm{C}$ at a heating rate of $10{ }^{\circ} \mathrm{C} / \mathrm{min}$ under a nitrogen gas flow of $40 \mathrm{~mL} /$ min. Thermogravimetric analysis (TGA) was performed with a Thermal Analysis TGA-2050 thermogravimetric analyzer at a heating rate of $10{ }^{\circ} \mathrm{C} / \mathrm{min}$ under a nitrogen or air atmosphere. The gas flow rate was $100 \mathrm{~mL} / \mathrm{min}$. Dynamic mechanical analysis (DMA) was performed with a PerkinElmer DMA 7e dynamic mechanical analyzer at a frequency of $1 \mathrm{~Hz}$ and a heating rate of $3{ }^{\circ} \mathrm{C} / \mathrm{min}$. Limited oxygen index (LOI) values were measured on a Stanton Redcraft flame meter. The percentage in the $\mathrm{O}_{2}-\mathrm{N}_{2}$ mixture deemed sufficient to sustain the flame was taken as the LOI.

\section{Preparation of the OG/DEP and OG/DICY Nanocomposites}

Nanocomposites were obtained from the curing of OG with DEP and DICY with various values of the number ratio of epoxide groups in $\mathrm{OG}$ over active hydrogen in the curing agent (i.e., $N$ $=2,1$, or 0.7 ). Predetermined amounts of $\mathrm{OG}$ and the curing agent (DEP or DICY) were dissolved in a solvent (tetrahydrofuran for DEP and $N, N$-dimethylformamide for DICY) to obtain a homogeneous solution. The solvent was evaporated out at $25{ }^{\circ} \mathrm{C}$ in vacuo. The residue was cured with a heating process of $150{ }^{\circ} \mathrm{C}$ for $1 \mathrm{~h}$, $180{ }^{\circ} \mathrm{C}$ for $1 \mathrm{~h}$, and $230{ }^{\circ} \mathrm{C}$ for $3 \mathrm{~h}$. For a comparison of the properties, a DDM-cured OG resin with $N=1$ (OG/DDM-1) was also prepared with the same procedure used for the OG/DEP preparation.

\section{Preparation of the OG-Modified Epoxy Resins Cured with DICY and DEP}

Predicted amounts of OG and BE188 were dissolved in THF. The solution was then mixed with solutions of the curing agent (DEP in THF or DICY in DMF) in stoichiometric ratios $(N$ $=1$ ). The solvent was evaporated out at $25{ }^{\circ} \mathrm{C}$ in vacuo. The residue was cured with a heating process of $150{ }^{\circ} \mathrm{C}$ for $1 \mathrm{~h}, 180{ }^{\circ} \mathrm{C}$ for $1 \mathrm{~h}$, and $230{ }^{\circ} \mathrm{C}$ for $3 \mathrm{~h}$.

Journal of Polymer Science: Part A: Polymer Chemistry DOI 10.1002/pola 


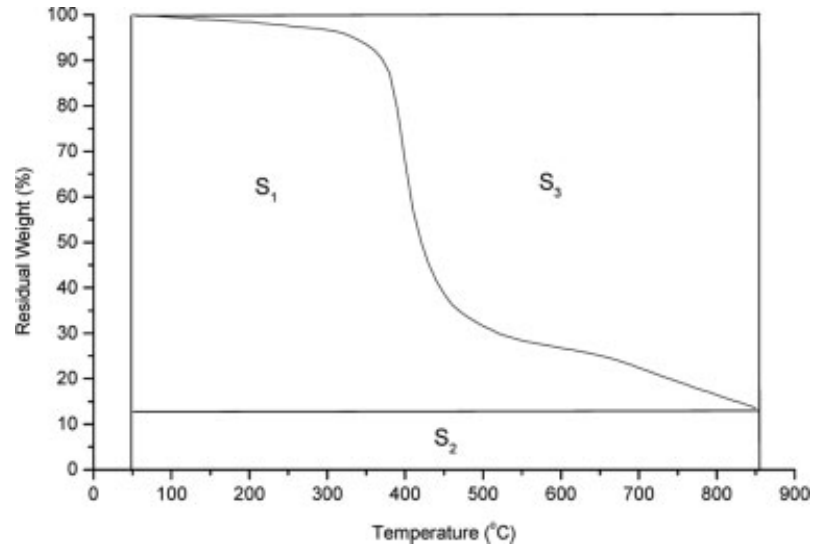

Figure 1. Representation of $S_{1}, S_{2}$, and $S_{3}$.

\section{Integrated Procedure Decomposition Temperature}

The integral procedure decomposition temperature $\left(\right.$ IPDT) ${ }^{41}$ was calculated as follows:

$$
\operatorname{IPDT}\left({ }^{\circ} \mathrm{C}\right)=A^{*} K^{*}\left(T_{\mathrm{f}}-T_{\mathrm{i}}\right)+T_{\mathrm{i}}
$$

where $A^{*}$ is the area ratio of the total experimental curve divided by the total TGA thermogram, $K^{*}$ is the coefficient of $A^{*}, T_{\mathrm{i}}$ is the initial experimental temperature, and $T_{\mathrm{f}}$ is the final experimental temperature. A representation of $S_{1}, S_{2}$, and $S_{3}$ for calculating $A^{*}\left[A^{*}=\left(S_{1}\right.\right.$ $\left.\left.+S_{2}\right) /\left(S_{1}+S_{2}+S_{3}\right)\right]$ and $K^{*}\left[K^{*}=\left(S_{1}+S_{2}\right) /\right.$ $S_{1}$ ] is shown in Figure 1.

\section{RESULTS AND DISCUSSION}

\section{Preparation of Epoxy Resins from OG Cured with DICY and DEP}

The chemical structures of the agents used in the preparation of the epoxy-POSS nanocomposites are shown in Figure 2. OG was cured with DICY or DEP with various values of $N$. Samples were obtained with the three $N$ values of 2.0 , 1.0, and 0.7. Figure 3 shows the FTIR spectra of the OG/DEP nanocomposites. The absorption peak of the OG epoxide groups $\left(909 \mathrm{~cm}^{-1}\right)$ was observed with OG/DEP-2 $(N=2.0)$ but not with OG/DEP-0.7 $(N=0.7)$. In the composition of OG/DEP-2, there were excess epoxide groups. Some epoxide groups did not participate in the curing reaction and remained in the nanocomposites. An increase in the amount of DEP consumed all the epoxide groups, and the epoxide absorption peak in the FTIR spectra of OG/ DEP-1 and OG/DEP-0.7 disappeared. Hydroxyl groups, which were generated from the curing reaction, were observed with the absorption peak at $3471 \mathrm{~cm}^{-1}$. An increase in the amount of DEP in the curing compositions increased this peak intensity and brought a redshift to this peak to $3417 \mathrm{~cm}^{-1}$, which indicated the generation of more hydroxyl groups and the formation of hydrogen bonding between the hydroxyl groups. Similar results were also observed for the OG/DICY nanocomposites.

All the prepared OG/DEP and OG/DICY nanocomposites exhibited good transparency, which indicated that no macrophase separation occurred in the curing period. The glass-transition behavior was not observed below $220{ }^{\circ} \mathrm{C}$ in the DSC measurements. Unfortunately, the samples were too brittle to be used in DMA measurements. The high brittleness of the nanocomposites was attributed to the use of small-molecule curing agents of DEP and DICY, which simultaneously shortened the chain lengths between the crosslinks and promoted the curing reaction conversion. In addition, the nanocomposites possessed very high POSS fractions. For the $N=1$ cases, the inorganic $\mathrm{SiO}_{x}$ fractions in the OG/DDM and OG/DICY nanocomposites, calculated from the curing compositions, were about 35.5 and 40.6 wt \%, respectively. An increase in the inorganic $\mathrm{SiO}_{x}$ fractions of the nanocomposites also was attributed to the increase in the brittleness.

The thermal stabilities of the OG/DEP, OG/ DICY, and OG/DDM nanocomposites were characterized with TGA (Fig. 4), and the analytical data are collected in Table 1 . All the samples exhibited similar degradation thermograms in

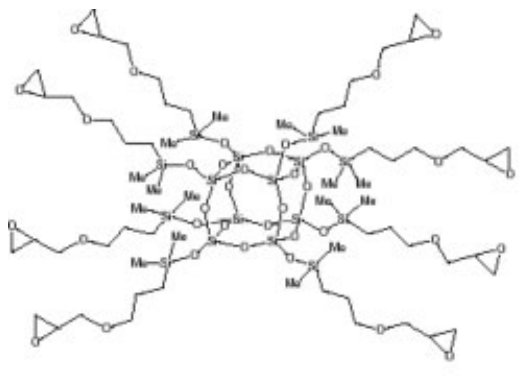

OG

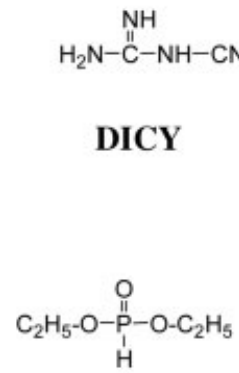

DEP
Figure 2. Chemical structures of the epoxide monomers and curing agents. 


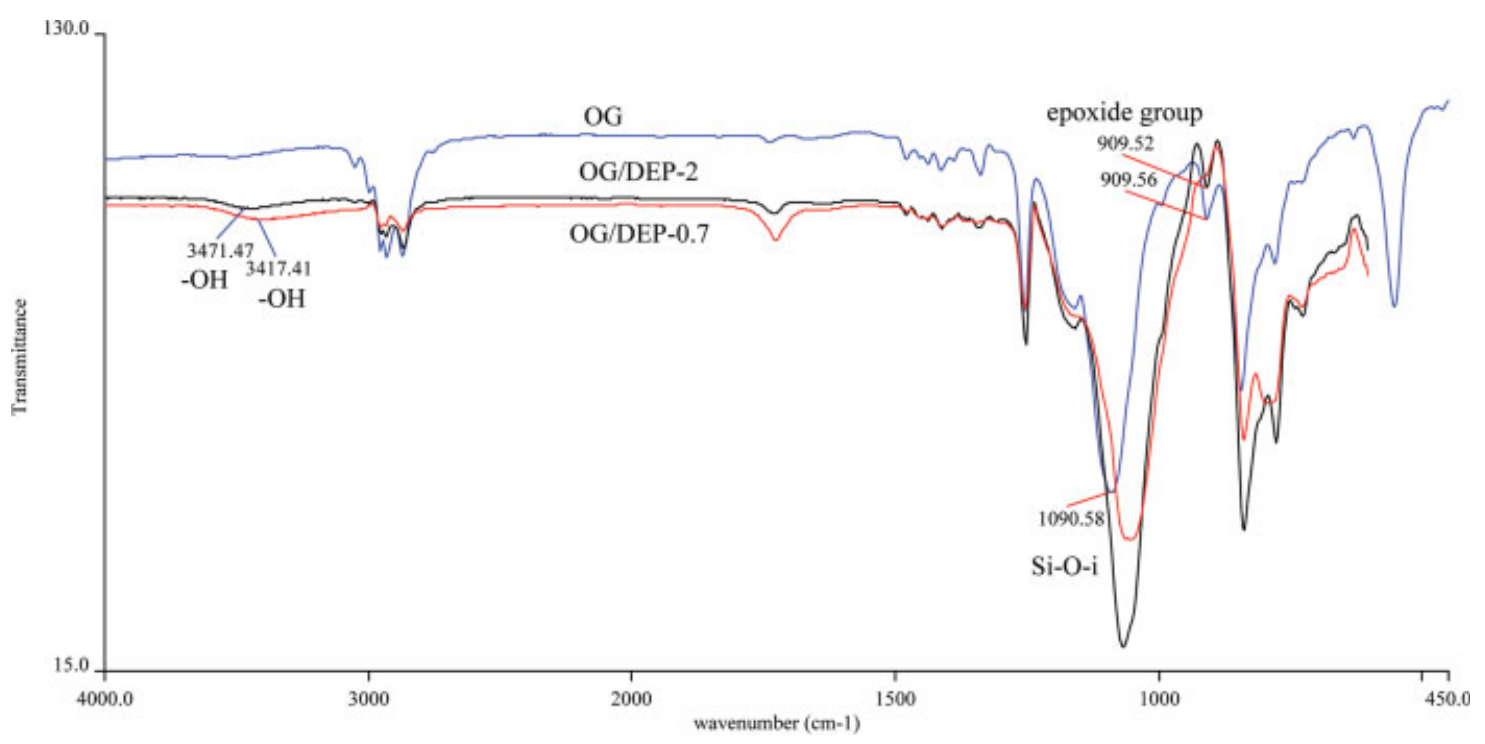

Figure 3. FTIR spectra of the OG/DEP nanocomposites. [Color figure can be viewed in the online issue, which is available at www.interscience.wiley.com.]

an atmosphere of $\mathrm{N}_{2}$. However, the relatively low degradation temperatures $\left(T_{\mathrm{d}}\right.$ 's; i.e., the temperatures at 5\% weight loss) of OG/DEP-1 came from their thermally unstable phosphonate groups. Besides, the char yields (residue amount at $800{ }^{\circ} \mathrm{C}$ ) of the nanocomposites were noteworthy. OG/DDM-1 showed the smallest char yield, which mainly was formed from its inorganic $\mathrm{SiO}_{x}$ fraction. However, OG/DEP-1 and OG/DICY-1, which possessed similar $\mathrm{SiO}_{x}$ fractions, showed different char yields. As the phosphonate group is known as a char-formation promoter, the relatively high char yield of OG/DEP-1 is understood with the phosphonate group action. The char enhancement was also observed with the DICY-cured nanocomposites because of nitrogen-silica synergism. ${ }^{42}$ The thermal degradation behaviors of the nanocomposites made with various $N$ values are shown as Figure 5. The weight loss started at very low temperatures $\left(100-250 \quad{ }^{\circ} \mathrm{C}\right)$ for all samples except OG/DICY-2 and OG/DEP-2, which possessed excess epoxide groups in the curing formulations. The low-temperature weight loss came from the residue curing agent after the curing reaction. The char yields decreased with increasing DICY amounts in the curing compositions because more DICY residue remained in OG/DICY-0.7. Moreover, though possessing many phosphonate groups, OG/DEP-0.7 did not exhibit the highest char yields among the nanocomposites. DEP was present in a large excess in the OG/DEP-0.7 formulation, but some DEP did not participate in the curing reaction, and so it was not incorporated into the crosslinked structure. The free DEP residue volatized at low temperatures before nanocomposite degradation and could not promote the char formation.

Figure 6 shows the SEM micrographs of the fracture surfaces of OG/DEP and OG/DICY nanocomposites frozen under cryogenic conditions with liquid nitrogen. No macrophase separation appeared for the samples. The fracture surface of OG/DICY-1, compared with other sample surfaces, was quite smooth. A smooth surface was also observed for OG/DEP-0.7. Nanocomposites with stoichiometric curing compositions exhibited good homogeneity. The use of small molecules as curing agents did not exclude the POSS cages during the curing reactions and

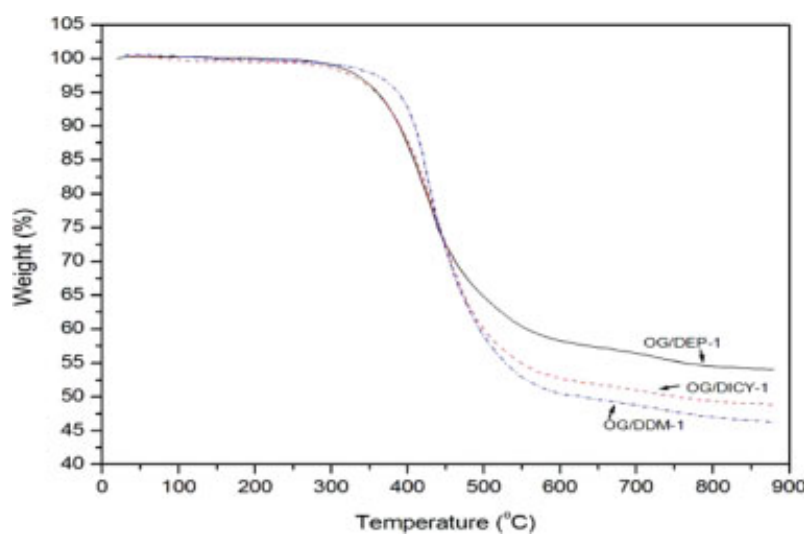

Figure 4. TGA thermograms of the OG nanocomposites in nitrogen.

Journal of Polymer Science: Part A: Polymer Chemistry DOI 10.1002/pola 
Table 1. Thermal Stability Data for OG-Based Nanocomposites from TGA

\begin{tabular}{|c|c|c|c|c|c|c|}
\hline \multirow[b]{2}{*}{ Sample } & \multirow[b]{2}{*}{$\begin{array}{l}\text { Curing } \\
\text { Agent }\end{array}$} & \multirow[b]{2}{*}{$N$} & \multicolumn{2}{|c|}{$\begin{array}{c}\text { TGA Data } \\
\text { under Nitrogen }\end{array}$} & \multicolumn{2}{|c|}{$\begin{array}{l}\text { TGA Data } \\
\text { under Air }\end{array}$} \\
\hline & & & $\begin{array}{l}T_{\mathrm{d}} \\
\left({ }^{\circ} \mathrm{C}\right)\end{array}$ & $\begin{array}{c}\text { Char Yield } \\
\text { at } 800{ }^{\circ} \mathrm{C}(\text { wt } \%)\end{array}$ & $T_{\mathrm{d}}\left({ }^{\circ} \mathrm{C}\right)$ & $\begin{array}{c}\text { Char Yield } \\
\text { at } 800{ }^{\circ} \mathrm{C}(\text { wt } \%)\end{array}$ \\
\hline OG/DEP-2 & DEP & 2 & 367 & 52 & 313 & 54 \\
\hline OG/DEP-1 & DEP & 1 & 356 & 60 & 306 & 55 \\
\hline OG/DEP-0.7 & DEP & 0.7 & 340 & 53 & 294 & 50 \\
\hline OG/DICY-2 & DICY & 2 & 365 & 53 & 338 & 45 \\
\hline OG/DICY-1 & DICY & 1 & 359 & 49 & 340 & 47 \\
\hline OG/DICY-0.7 & DICY & 0.7 & 355 & 48 & 332 & 42 \\
\hline OG/DDM-1 & DDM & 1 & 388 & 47 & 349 & 40 \\
\hline
\end{tabular}

prevented the occurrence of macrophase separation.

\section{OG-Modified Epoxy Resins Cured with DICY and DEP: Preparation and Morphology}

These results suggest that the use of small molecules to cure OG can enhance the curing reaction conversion and the nanocomposite homogeneity. However, the nanocomposites are highly brittle because of the short chain lengths in the crosslinked structure. The rigid structure of POSS also contributes to the brittleness of the nanocomposites as they possess high POSS contents. For the purpose of developing high-performance epoxy resins, OG was used as a reactive modifier to cocure with the conventional DGEBA epoxy resin (BE188). OG/BE188 mixtures with various $O G$ contents were cured with DEP and DICY for the preparation of OG-BE nanocomposites. The epoxy and curing agents were in stoichiometric ratios $(N=1)$ in the formulations. The preparation compositions of the OG-modified epoxy resins are listed in Table 2. The samples are coded as OG-BE/DEP-M and OG-BE/DICY-M, where M is the OG weight percentage in the curing mixtures.

None of the OG-BE nanocomposite samples showed epoxy group absorption (ca. 905-910 $\mathrm{cm}^{-1}$ ) in their FTIR spectra (figures not shown), and this indicated the high curing reaction conversions. The OG-BE nanocomposite homogeneity was examined with SEM (Fig. 7). Smooth surfaces were observed for the OG-BE nanocomposites. The fracture surface morphologies observed for the pristine BE188-cured resin and OG-BE nanocomposites were similar, indicating the good homogeneity of the OG-BE nanocomposites. OG addition in the BE188/DEP and BE188/DICY curing compositions did not induce phase separation during the mixing and curing reaction periods. DEP and DICY are proper curing agents for the preparation of OG-BE nanocomposites having high OG contents.

\section{OG-Modified Epoxy Resins Cured with DICY and DEP: Thermal Properties}

Figure 8 shows the DSC thermograms of the OG-BE nanocomposites. No exothermic peaks appeared in the thermograms, and this indicated that no reactive epoxide residues were present in the nanocomposites and that the curing reaction conversions were high. Glass-transition behaviors were observed with the samples. Neat DGEBA/DEP resin (OG-BE/DEP-0) showed its $T_{\mathrm{g}}$ at $90{ }^{\circ} \mathrm{C}$. The addition of $\mathrm{OG}$ in

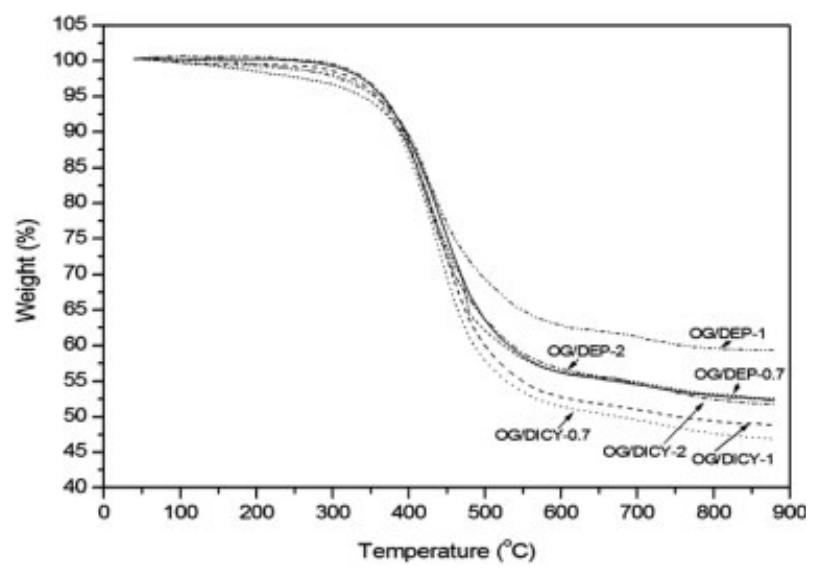

Figure 5. TGA thermograms of the OG/DEP and OG/DICY nanocomposites. 

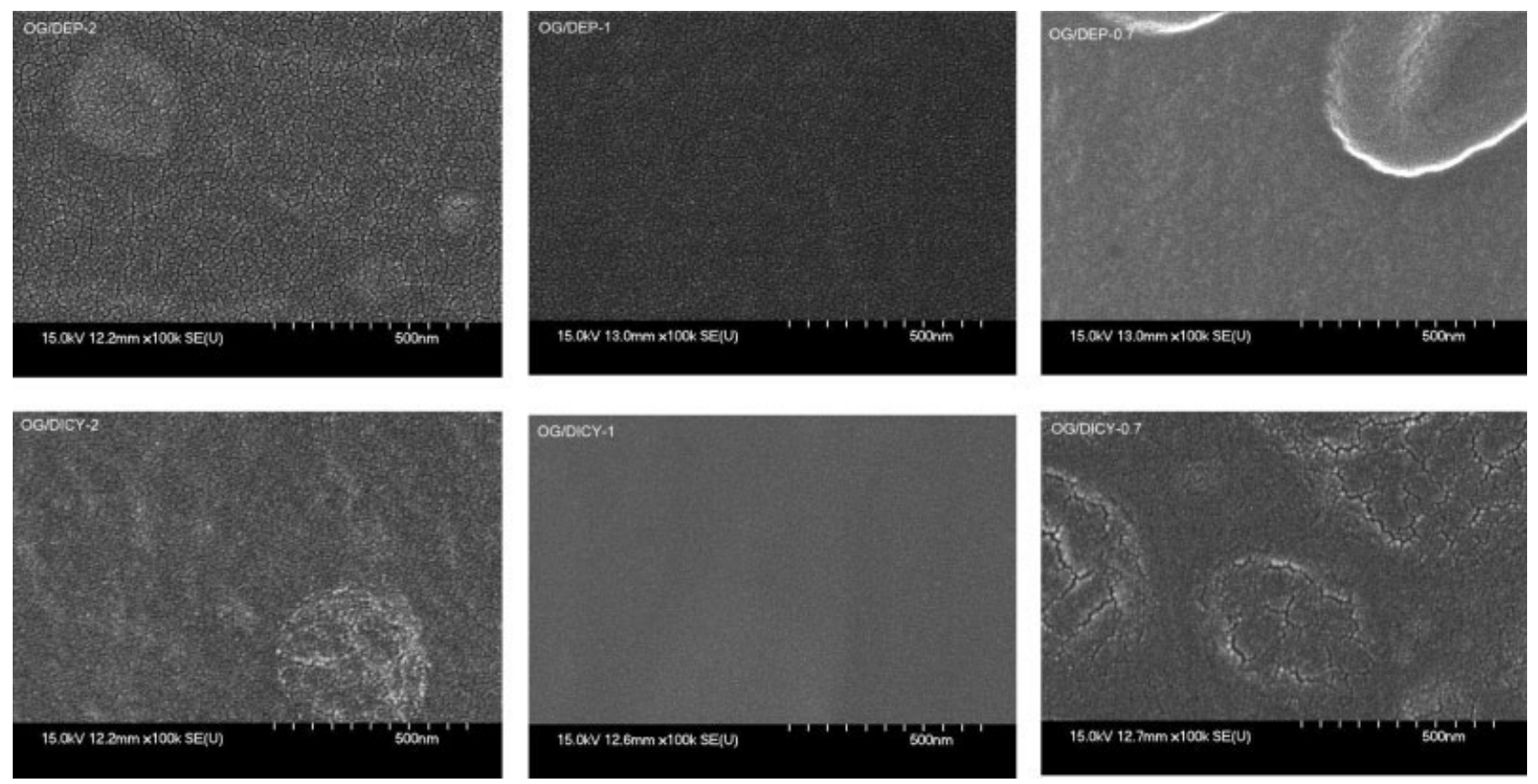

Figure 6. SEM micrographs of the OG/DEP and OG/DICY nanocomposite fracture surfaces.

the curing formulation depressed the $T_{\mathrm{g}}$ 's of the nanocomposites. The depression amplitude increased with increasing OG amounts, as the $T_{\text {g }}$ observed for OG-BE/DEP-35 was $73{ }^{\circ} \mathrm{C}$. Li et al. ${ }^{43}$ reported that an epoxy/POSS composite (25 wt \% POSS) exhibited a lower $T_{\mathrm{g}}$ than the neat epoxy resin. Similar results were also reported by Ni et al. ${ }^{30}$ The $T_{\mathrm{g}}$ 's of the epoxy/POSS nanocomposites decreased with an increasing concentration of POSS. Li et al. ascribed the decrease

Table 2. Preparation Compositions and Thermal Properties of OG-Modified Epoxy-POSS Nanocomposites

\begin{tabular}{|c|c|c|c|c|c|c|c|c|}
\hline \multirow[b]{2}{*}{ Sample } & \multirow[b]{2}{*}{$\begin{array}{c}\text { Curing } \\
\text { Composition } \\
\text { (OG/BE188/ } \\
\text { Curing Agent) } \\
\text { by Weight (g) }\end{array}$} & \multirow[b]{2}{*}{$\begin{array}{c}T_{\mathrm{g}} \text { from } \\
\mathrm{DSC}\left({ }^{\circ} \mathrm{C}\right)\end{array}$} & \multicolumn{3}{|c|}{$\begin{array}{l}\text { TGA Data under } \\
\text { Nitrogen }\end{array}$} & \multirow[b]{2}{*}{ LOI } & \multicolumn{2}{|c|}{ DMA Data } \\
\hline & & & $\begin{array}{c}T_{\mathrm{d}} \\
\left({ }^{\circ} \mathrm{C}\right)\end{array}$ & $\begin{array}{l}\text { Char } \\
\text { Yield at } \\
800{ }^{\circ} \mathrm{C} \\
(\text { wt \%) }\end{array}$ & $\begin{array}{c}\text { IPDT } \\
\left({ }^{\circ} \mathrm{C}\right)\end{array}$ & & $\begin{array}{l}\text { Storage } \\
\text { Modulus } \\
\text { at } 50{ }^{\circ} \mathrm{C} \\
(\mathrm{MPa})\end{array}$ & $\begin{array}{l}T_{\mathrm{g}} \text { from } \\
\text { the Tan } \delta \\
\text { Peak } \\
\left({ }^{\circ} \mathrm{C}\right)\end{array}$ \\
\hline OG-BE/DEP-0 & $0: 10: 2.5$ & 89 & 342 & 22 & 778 & 24 & 430 & 102 \\
\hline OG-BE/DEP-5 & $0.35: 5: 1.3$ & 90 & 332 & 23 & 802 & 26 & 600 & 83 \\
\hline OG-BE/DEP-10 & $0.9: 6: 1.6$ & 90 & 320 & 25 & 836 & 28 & 930 & 80 \\
\hline OG-BE/DEP-15 & $1.2: 5: 1.5$ & 87 & 316 & 28 & 925 & 30 & 530 & 80 \\
\hline OG-BE/DEP-20 & $1.7: 5: 1.5$ & 83 & 305 & 30 & 973 & 31 & - & - \\
\hline OG-BE/DEP-35 & $3.7: 5: 2$ & 72 & 332 & 37 & 993 & 29 & - & - \\
\hline OG-BE/DEP-54 & $6.0: 3: 2$ & - & 350 & 41 & 1400 & 29 & - & - \\
\hline OG-BE/DICY-0 & $0: 10: 1.1$ & 130 & 332 & 11 & 552 & 23 & 480 & 147 \\
\hline OG-BE/DICY-5 & $0.35: 6: 0.7$ & 147 & 340 & 16 & 670 & 25 & 330 & 160 \\
\hline OG-BE/DICY-10 & $0.8: 6: 0.8$ & 132 & 335 & 18 & 695 & 26 & 140 & 152 \\
\hline OG-BE/DICY-15 & $1: 5: 0.6$ & 118 & 333 & 20 & 737 & 27 & 65 & 137 \\
\hline OG-BE/DICY-20 & $1.5: 5: 0.7$ & 131 & 349 & 23 & 830 & 28 & 50 & 150 \\
\hline OG-BE/DICY-35 & $3: 4.7: 0.8$ & - & 346 & 30 & 989 & 26 & 720 & 156 \\
\hline OG-BE/DICY-54 & $5: 3.5: 0.8$ & - & 358 & 38 & 1252 & 25 & - & - \\
\hline
\end{tabular}



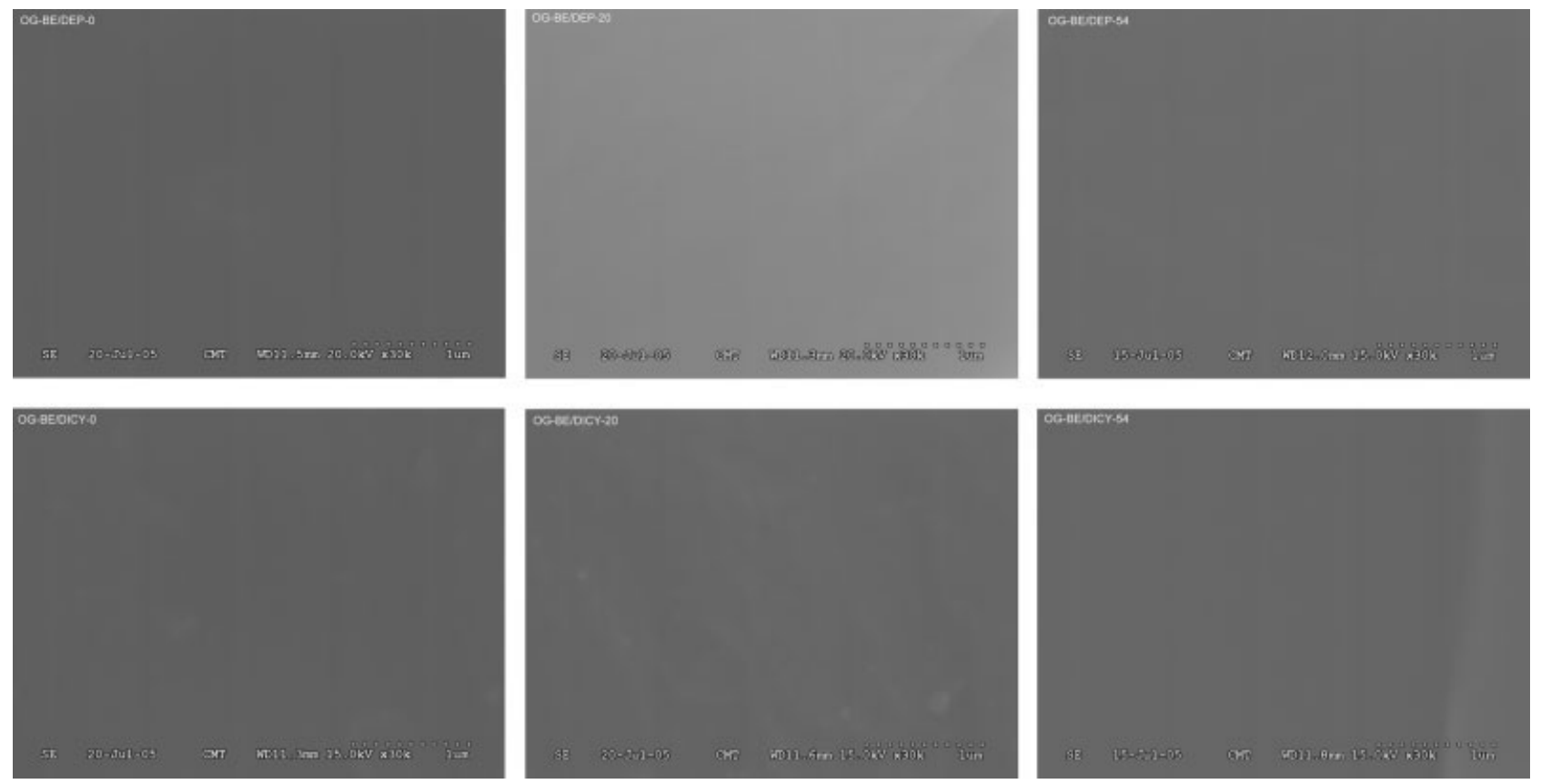

Figure 7. SEM micrographs of the OG-BE/DEP and OG-BE/DICY nanocomposite fracture surfaces.

in $T_{\mathrm{g}}$ to an incomplete curing reaction of epoxy groups. As mentioned in the previous paragraph, the degree of the curing reaction measured with FTIR in this work was very high. The decrease in $T_{\mathrm{g}}$ observed in this work could be attributed to the fact that the bulky POSS cages separated the polymer chains. ${ }^{44,45}$ This chain separation also prevented interchain hydrogenbond formation and so reduced nanocomposite $T_{\mathrm{g}}$ 's. ${ }^{21}$ However, glass-transition behavior disap- peared for $\mathrm{OG}-\mathrm{BE} / \mathrm{DEP}-54$. In this case, the POSS concentration was high, above which the interchain interactions and inertia effect of a large mass of POSS molecules were responsible for the retardation of polymer chain motion. ${ }^{29,46}$ On the other hand, the OG-BE/DICY nanocomposites exhibited a different $T_{\mathrm{g}}$ variation behavior. A small amount of OG (5 wt \%) increased $T_{\mathrm{g}}$ of the epoxy resins from 130 (OG-BE/DICY-0) to $147{ }^{\circ} \mathrm{C}$ (OG-BE/DICY-5). The $T_{\mathrm{g}}$ increase could
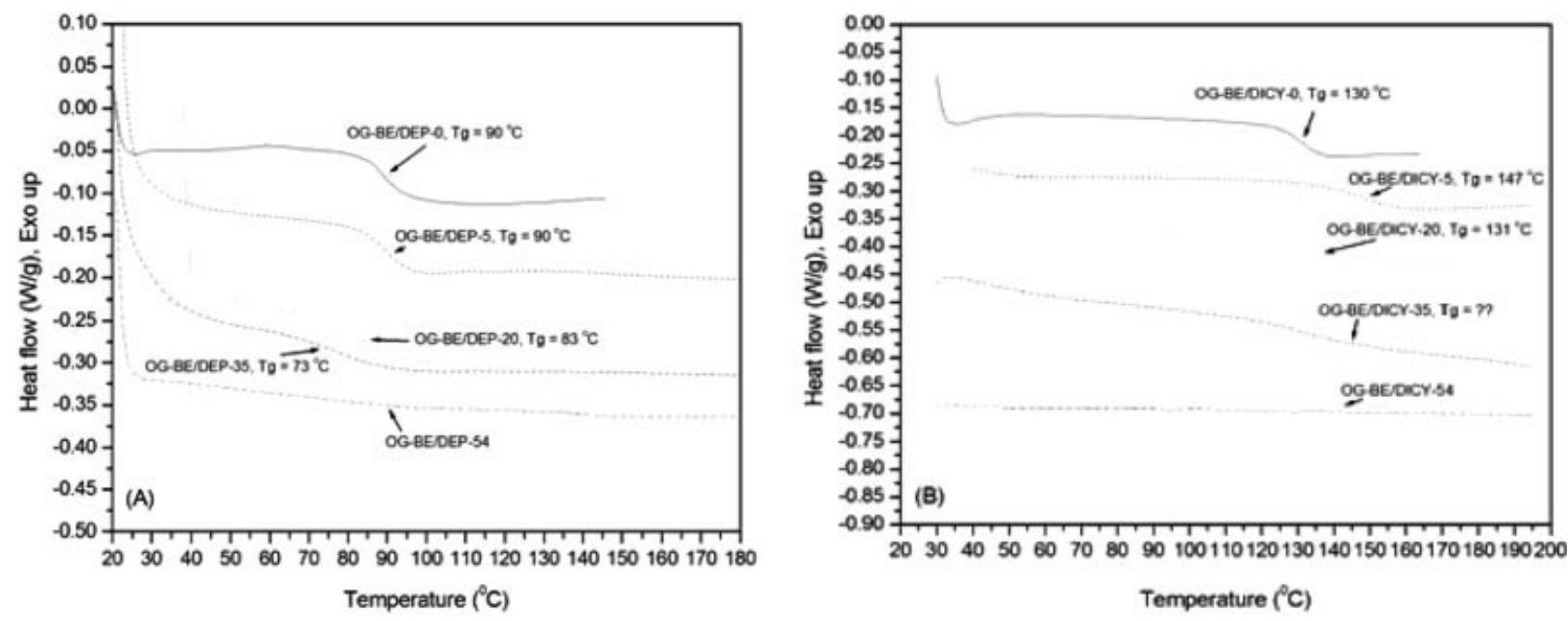

Figure 8. DSC thermograms of OG-modified DGEBA-POSS nanocomposites: (A) OG-BE/GEP and (B) OG-BE/DICY nanocomposites. 

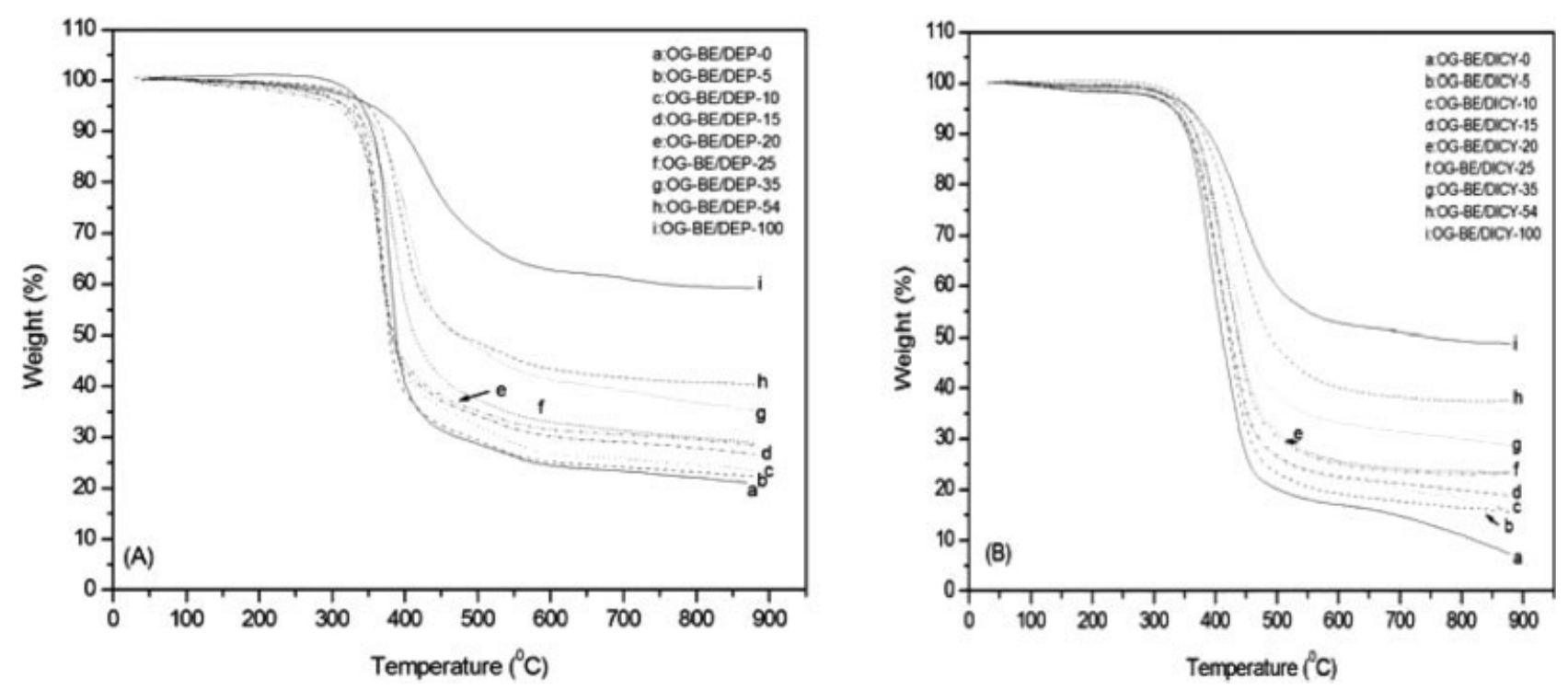

Figure 9. TGA thermograms (in nitrogen) of OG-modified DGEBA-POSS nanocomposites: (A) OG-BE/DEP and (B) OG-BE/DICY nanocomposites.

be attributed to the multifunctional epoxide groups in OG. ${ }^{13}$ This effect was also observed with OG-BE/DEP-5, as its $T_{\mathrm{g}}$ was similar to that of the neat epoxy resin OG-BE/DEP-0. More OG addition in the BE188/DICY compositions reduced their $T_{\mathrm{g}}$ 's. Similarly to $\mathrm{OG}-\mathrm{BE} /$ DEP-54, glass-transition behavior disappeared for OG-BE/DICY-54. POSS-polymer chain interactions in the high POSS-fractioned nanocomposites slowed down chain relaxation and restrained the chain motion and glass-transition behavior. ${ }^{29,46}$

The thermal stability and degradation behavior of the nanocomposites were examined with TGA (Table 2). The nanocomposites in the same series exhibited similar degradation patterns upon heating in nitrogen and showed high $T_{\mathrm{d}}$ 's above $300{ }^{\circ} \mathrm{C}$ (Fig. 9). Besides the initial $T_{\mathrm{d}}$ value, the integral procedural degradation temperature (IPDT) could be another parameter used for the evaluation of the polymer thermal stability. IPDT can provide information about the amounts of volatile parts of polymeric materials as well as the inherent thermal stability of polymers. ${ }^{41}$ Moreover, Liu et al. ${ }^{47}$ established the relationship between IPDT and flammability for polymers. Figure 10 presents the relationship between the char yields (residue at $800{ }^{\circ} \mathrm{C}$ in TGA measurements) and IPDT values and the nanocomposite $\mathrm{OG}$ fractions. Both the char yields and IPDT values almost linearly increased with increasing OG fractions for both series of nanocomposites. As previously mentioned, the phosphonate group in DEP is a char- formation promoter. The relatively high char yields and high IPDT values are reasonable. POSS addition to epoxy resins significantly increased their char yields and IPDT values. High char yields correspond to reduced amounts of volatile and combustible compounds evolving from the thermal degradation processes and improved flammability. The improved flammability was demonstrated by the increases in the LOI values (Table 2) The addition of 20 wt \% OG-POSS to the curing composition leveled up the resin LOI values from 24 to 31 and from 23 to 28 for the OG-BE/DEP and OG-BE/DICY

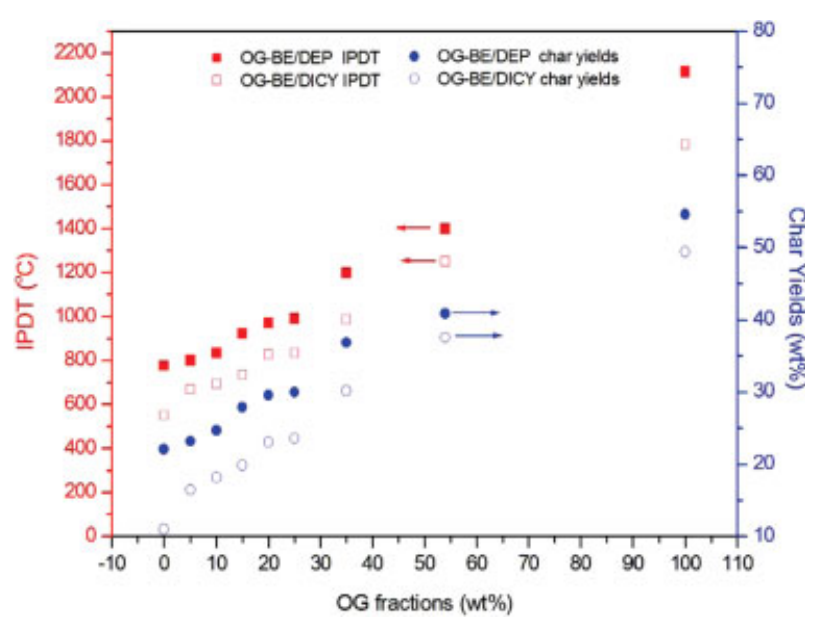

Figure 10. Plots of the char yields and IPDT values of the OG-BE nanocomposites versus their OG fractions. [Color figure can be viewed in the online issue, which is available at www.interscience.wiley.com.]

Journal of Polymer Science: Part A: Polymer Chemistry DOI 10.1002/pola 


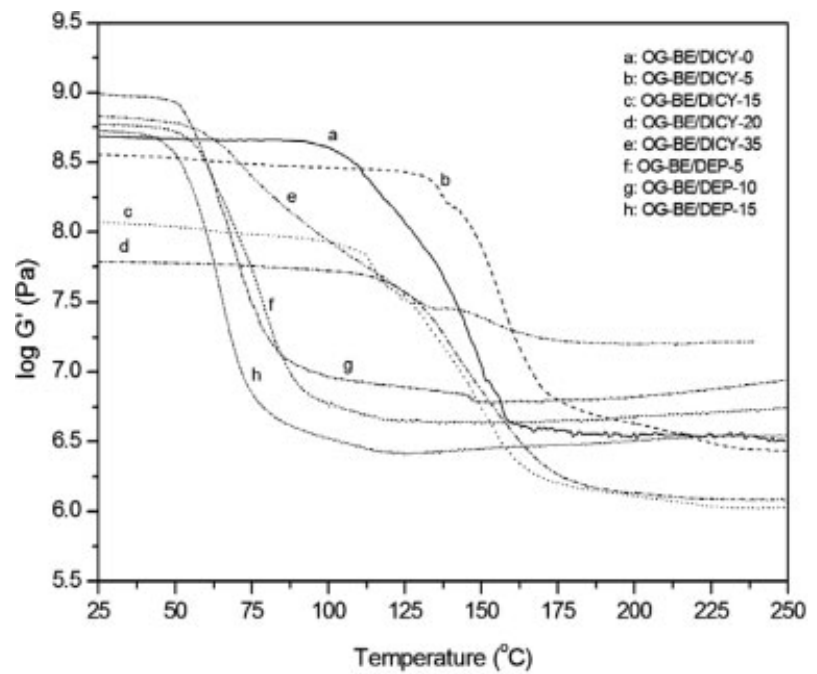

Figure 11. DMA thermograms of some OG-modified DGEBA-POSS nanocomposites. G': storage modulus.

resins, respectively. However, the thermally unstable and highly volatile propyl glycidyl ether groups in OG-POSS contributed a counteraction to flammability improvement. Therefore, nanocomposites possessing OG-POSS contents above 20 wt \% did not exhibit higher LOI values. Moreover, the char yields of the nanocomposites were much higher than their POSS fractions, and this indicated some organic parts were kept in char residue after degradation through the nitrogen-silicon and phosphorus-silicon synergisms of char formation. ${ }^{48-50}$ The synergisms have been proposed to perform through a silicon migration mechanism to the material surface with the formation of a thermally stable layer on the material surface. ${ }^{38}$ However, different silicon materials behave in different ways. Organosilicon compounds and silica generated from sol-gel processes show silicon migration under heating, and silica nanoparticles do not. ${ }^{38}$ These results indicate that silicon in POSS can migrate to the matrix surface under heating to alter the degradation mechanisms of the organic parts in epoxy-POSS nanocomposites.

\section{OG-Modified Epoxy Resins Cured with DICY and DEP: Mechanical Properties}

The thermomechanical properties of the OG-BE nanocomposites were measured with DMA. The DMA thermograms are shown in Figure 11. The $T_{\mathrm{g}}$ 's obtained from the $\tan \delta$ peaks agreed with the values from the DSC measurements (Table 2 ). The discussion on the glass-transition behavior of nanocomposites is interpreted in the previous section. Except for OG-BE/DICY-15 and OG-BE/DICY-20, the storage moduli of the nanocomposites were comparable to or higher than that of the neat epoxy resins. Increases in both the crosslinking density and POSS fraction in the nanocomposites may have contributed to the storage modulus increase. As the storage modulus did not increase with an increase in the POSS fractions, high POSS fractions might limit curing reaction completion and reduce crosslinking density. For the nanocomposites possessing the same POSS fractions, the DEPcured nanocomposites exhibited higher storage moduli and crosslinking density than the DICYcured samples did. As DICY is a tetrafunctional curing agent and DEP is trifunctional, DICYcured nanocomposites might possess high crosslinking density. However, the curing reaction of DEP with epoxide compounds could be performed through a cationic mechanism. ${ }^{51,52} \mathrm{DEP}$ serves not only as a curing reactant but also as a cationic initiator in the curing reaction and so increases the possibility of forming interchain linkages. However, this cationic reaction couples two glycidyl ether groups and extends the flexible chain lengths to reduce the $T_{\mathrm{g}}$ 's of DEPcured nanocomposites (Scheme 1).

Besides the glassy-state storage modulus, the storage modulus above $T_{\mathrm{g}}$ is directly correlated to the crosslinking density of polymers. DEPcured nanocomposites also showed a high rubbery-state modulus (storage modulus above $T_{\mathrm{g}}$ ), and this indicated their high crosslinking densities. On the other hand, a dramatic increase in the rubbery-state storage modulus was observed

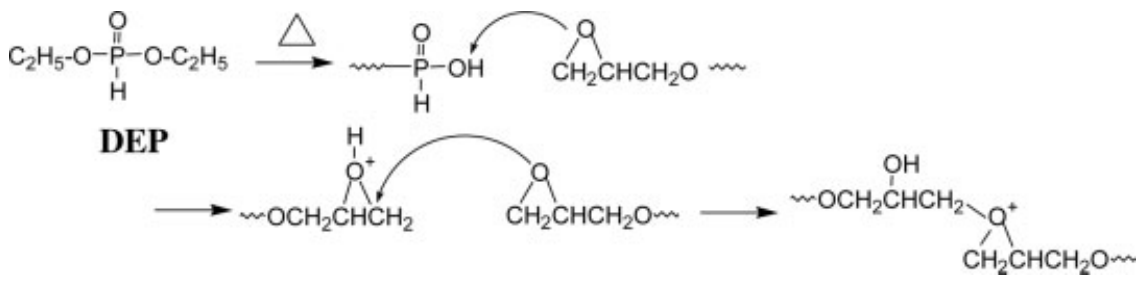

Scheme 1

Journal of Polymer Science: Part A: Polymer Chemistry

DOI 10.1002/pola 
with OG-BE/DICY-35, which possessed a relatively high OG fraction. The high rubber modulus indicated high crosslinking density in OGBE/DICY-35. The structure of OG consists of eight epoxy groups, which are favorable for incorporation with a curing agent to some extent. ${ }^{26}$ The addition of more OG to the curing compositions promoted this action and increased the crosslinking density of the nanocomposites. The high POSS fraction in OG-BE/DICY-35 also broadened its glass-transition behavior with the formation of a small shoulder in its storage thermogram [Fig. 11(e)]. The chains in the epoxyrich domain moved in the low-temperature region. Chain motion in the POSS-rich domain was restricted to start at high temperatures above $T_{\mathrm{g}}$ of the neat epoxy resin. Moreover, the broad glass-transition behavior could also suggest the occurrence of phase segregation of the POSS domain on a nanoscale. This phase segregation occurred only for nanocomposites having high POSS fractions, as nanocomposites possessing less than $35 \%$ OG did not show such phase segregation.

\section{CONCLUSIONS}

The use of small molecules as curing agents promoted the homogeneity of OG-epoxy nanocomposites. However, OG/DEP and OG/DICY nanocomposites were brittle. OG addition to BE188/ DEP and BE188/DICY curing compositions resulted in epoxy-POSS nanocomposites with a high OG loading of $54 \mathrm{wt} \%$. The nanocomposites possessing high OG contents exhibited good thermal stability, improved flammability, and high storage moduli.

Financial support from the National Science Council of Taiwan (grant no. NSC-93-2216-E-033-003) and the Center-of-Excellence Program on Membrane Technology from the Ministry of Education of Taiwan is highly appreciated.

\section{REFERENCES AND NOTES}

1. LeBaron, P. C.; Wang, Z.; Pinnavaia, T. J. Appl Clay Sci 1999, 15, 11.

2. Sellinger, A.; Laine, R. M. Macromolecules 1996, 29, 2327.

3. Zhang, C.; Babonneau, F.; Bonhomme, C.; Laine, R. M.; Soles, C. L.; Hristov, H. A.; Yee, A. F. J Am Chem Soc 1998, 120, 8380.
4. Zhang, C.; Laine, R. M. J Am Chem Soc 2000, $122,6979$.

5. Liang, K.; Toghiani, H.; Li, G.; Pittman, C. U., Jr. J Polym Sci Part A: Polym Chem 2005, 43, 3887.

6. Li, G. Z.; Cho, H.; Wang, L.; Toghiani, H.; Pittman, C. U., Jr. J Polym Sci Part A: Polym Chem 2005, 43, 355.

7. Isayeva, I. S.; Kennedy, J. P. J Polym Sci Part A: Polym Chem 2004, 42, 4337.

8. Wahab, M. A.; Kim, I.; Ha, C. S. J Polym Sci Part A: Polym Chem 2004, 42, 5189.

9. Liu, Y.; Zheng, S. J Polym Sci Part A: Polym Chem 2006, 44, 1168.

10. Laine, R. M.; Choi, J.; Lee, I. Adv Mater 2001, 13,800 .

11. Krishnan, P. S. G.; He, C.; Shang, C. T. S. J Polym Sci Part A: Polym Chem 2004, 42, 4036.

12. Ohno, K.; Sugiyama, S.; Koh, K.; Tsujii, Y.; Fukuda, T.; Yamahiro, M.; Oikawa, H.; Yamamoto, Y.; Ootake, N.; Watanabe, K. Macromolecules 2004, 37, 8517.

13. Krishnan, P. S. G.; He, C. J Polym Sci Part A: Polym Chem 2005, 43, 2483.

14. Huang, J.; Xiao, Y.; Mya, K. Y.; Liu, X.; He, C.; Dai, J.; Siow, Y. P. J Mater Chem 2004, 14, 2858.

15. Choi, J.; Tamaki, K.; Kim, S. G.; Laine, R. M. Chem Mater 2003, 15, 3365.

16. Tamaki, R.; Choi, J.; Laine, R. M. Chem Mater 2003, 15, 793.

17. Lee, A.; Lichtenhan, J. D. Macromolecules 1998, 31,4970 .

18. Fu, B. X.;. Namani, M.; Lee, A. Polymer 2003, 44, 7739 .

19. Abad, M. J.; Barral, L.; Fasce, D. P.; Williams, R. J. J. Macromolecules 2003, 36, 3128.

20. Sellinger, A.; Laine, R. M. Chem Mater 1996, 9, 1592.

21. Choi, J.; Harcup, J.; Yee, A. F.; Zhu, Q.; Laine, R. M. J Am Chem Soc 2001, 123, 11420.

22. Choi, J.; Yee, A. F.; Laine, R. M. Macromolecules 2003, 36, 5666.

23. Choi, J.; Kim, S. G.; Laine, R. M. Macromolecules 2004, 37, 99.

24. Choi, J.; Yee, A. F.; Laine, R. M. Macromolecules 2004, 37, 3267.

25. Strachota, A.; Kroutilová, I.; Kovářová, J.; Matějka, L. Macromolecules 2004, 37, 9457.

26. Mya, K. Y.; He, C.; Huang, J.; Xiao, Y.; Dai, J.; Siow, Y. P. J Polym Sci Part A: Polym Chem 2004, 42,3490

27. Lee, A.; Lichtenhan, J. D. J Appl Polym Sci 1999, 73, 1993.

28. Kim, G. M.; Qin, H.; Fang, X.; Sun, F. C.; Mather, P. T. J Polym Sci Part B: Polym Phys 2003, 41, 3299.

29. Matějka, L.; Strachota, A.; Pleštil, J.; Whelan, P.; Steinhart, M.; Šlouf, M. Macromolecules 2004, 37, 9449.

30. Ni, Y.; Zheng, S.; Nie, K. Polymer 2004, 45, 5557. 
31. Chen, W. Y.; Wang, Y. Z.; Kuo, S. W.; Huang, C. F.; Tung, P. H.; Chang, F. C. Polymer 2004, 45, 6897.

32. Liu, H.; Zhang, W.; Zheng, S. Polymer 2005, 46, 157.

33. Dodiuk, H.; Kenig, S.; Blinsky, I.; Dotan, A.; Buchman, A. Int J Adhes Adhes 2005, 25, 211.

34. Lee, L. H.; Chen, W. C. Polymer 2005, 46, 2163.

35. Huang, J.; He, C.; Liu, X.; Xu, J.; Tay, C. S. S.; Chow, S. Y. Polymer 2005, 46, 7018.

36. Liu, Y. L.; Chang, G. P. J Polym Sci Part A: Polym Chem 2006, 44, 1869.

37. Chiu, Y. S.; Liu, Y. L.; Wei, W. L.; Chen, W. Y. J Polym Sci Part A: Polym Chem 2003, 41, 432.

38. Liu, Y. L.; Chou, C. I. Polym Degrad Stab 2005, 90, 515.

39. Liu, Y. L. J Polym Sci Part A: Polym Chem 2002, 40, 359.

40. Liu, Y. L.; Chang, G. P.; Wu, C. S.; Chiu, Y. S. J Polym Sci Part A: Polym Chem 2005, 43, 5787.

41. Doyle, C. D. Anal Chem 1961, 33, 77.

42. Wu, C. S.; Liu, Y. L.; Chiu, Y. C.; Chiu, Y. S. Polym Degrad Stab 2002, 78, 41.
43. Li, G. Z.; Wang, L.; Toghiani, H.; Daulton, T. L.; Koyama, K.; Pittman, C. U., Jr. Macromolecules 2001, 34, 8686.

44. Xu, H. Y.; Kuo, S. W.; Lee, J. S.; Chang, F. C. Macromolecules 2002, 35, 8788.

45. Haddal, T. S.; Lee, A.; Phillips, S. H. Polym Prepr 2001, 42(1), 88.

46. Romo-Uribe, A.; Mather, P. T.; Haddad, T. S.; Lichtenhan, J. D. J Polym Sci Part B: Polym Phys 1998, 36, 1857.

47. Liu, Y. L.; Wei, W. L.; Hsu, K. Y.; Ho, W. H. Thermochim Acta 2004, 412, 139.

48. Liu, Y. L.; Wu, C. S.; Chiu, Y. S.; Ho, W. H. J Polym Sci Part A: Polym Chem 2003, 41, 2354.

49. Chiang, C. L.; Ma, C. C. M. Polym Degrad Stab 2004, 83, 207.

50. Wu, C. S.; Liu, Y. L.; Chiu, Y. S. Polymer 2002, $43,4277$.

51. Kim, M.; Sanda, F.; Endo, T. Macromolecules 2000, 33, 3499.

52. Kim, M.; Sanda, F.; Endo, T. Macromol Chem Phys 2000, 201, 1691. 